\title{
The making of Wallace's Everything and More: an interview with Erica Neely
}

\author{
Stuart James Taylor ${ }^{1}$
}

Published online: 12 January 2016

(c) The Author(s) 2016. This article is published with open access at Springerlink.com

\begin{abstract}
Of all the works by celebrated author David Foster Wallace, his 'popular mathematics' book on Georg Cantor is by far the most neglected. Everything and More: A compact history of Infinity has proven difficult to reconcile with both Wallace's fiction and non-fiction alike. This interview article aims to shed some light on the nature and construction of Everything and More. First introducing the book in context by reconstructing from Wallace's personal letters its production, it then benefits from the unique insight of Wallace's technical adviser on the project, mathematician-turned-philosopher Erica Neely. Over the course of the interview, Wallace's motivations as well as his research and compositional strategy are exposed as Neely reflects on her time working with the author. This unique exposition and reflection paves the way for future dialogue about Everything and More that we may fully appreciate and understand this complex 'oddity' at the centre Wallace's oeuvre.
\end{abstract}

Keywords David Foster Wallace - Mathematics .

Literature · Georg Cantor · Erica Neely

\section{The making of Wallace's Everything and More: an interview with Erica Neely}

Late in the first summer of our millennium, publishers W.W. Norton pursued a range of writers for a new series of popular-science books, 'Great Discoveries'. Series editor,

Stuart James Taylor

s.taylor.2@ research.gla.ac.uk

1 Department of English Literature, University of Glasgow, 5 University Gardens, Glasgow G12 8QH, Scotland, UK
Jesse Cohen, envisioned 'novelists and scientists and science writers and nonfiction writers in a kind of grand conversation' that would infuse historical-science classroom staples with 'fresh energy'. This was the brief David Foster Wallace received on 8 August 2000. Cohen had then recently approached Wallace through his agent, Bonnie Nadell, to recruit the novelist for the 'Great Discoveries' series. With his passionate admiration for foundational set theorist Georg Cantor, Wallace clearly had his interest piqued by Cohen's project. Before committing to the project, Wallace had written to Cohen eight or so questions betraying his anxieties and excitement. 'Could I see a list of the series, including who's doing what? If any of the others on the list are done already, could you note which ones so I could maybe ask to look at one or two of the books?' 'Ummm, well, actually, ahhh... we, ahem!, we haven't actually signed anyone up yet!' was Cohen's fauxsheepish response. It is understandable that Wallace was anxious over who his co-contributors to the series would be: he was by no means a scientist and here he was being asked to produce a popular-scientific account. Cohen, Wallace then asked, 'Do you know that I can't read German?', to which Cohen replied that if 'the question has the deeper significance of your worrying about whether you can rely on translations and glosses and still write a rigorous and intellectually honest book, then I would just say that your conscientiousness is admirable and in line with our own wishes. ${ }^{1}$ Enamoured of his fiction and under the belief that the novelist had 'a mathematics background,' Cohen nevertheless believed Wallace to be 'exactly the kind of writer we are looking for: someone who can understand the science and convey it to the general reader.'

\footnotetext{
$\overline{1}$ Quotations from Wallace's work and correspondence are used with permission of the David Foster Wallace Literary Trust.
} 
Cohen suggested that, due to his expectance 'that this series is going to be around for a while, we can be flexible about due dates', though he aimed to publish the first entry 'in the fall of 2002, or early 2003. So we can work within your schedule'. Wallace followed up on this brief in a phone call on the first of October, clarifying the maximumpage limit of 250 pages $^{2}$ and that Cohen was more interested that Wallace write about the 'Intuitionism vs. Formal Platonism' debate, rather than 'a lot of technical symbolism-Trig Functions', in order to keep the book 'pitched to the General Reader'.

For the past 7 years (since 1993) Wallace had been teaching English at Illinois State University, in the department's Unit for Contemporary Fiction, at their Bloomington-Normal campus, 'about an hour from where he had grown up' [5, pp. 173-178]. Around the time of his initial correspondence with Cohen (in the 'fall of 2000' [5, pp. 266]), Wallace was offered a chair in creative writing at Pomona College, Claremont, California. Feeling 'tired' at Illinois State, Wallace accepted the position at Pomona while committed to fulfilling his teaching requirements at ISU for another year [5, p. 267]. In his final semester at ISU, D.T. Max writes, Wallace 'had pushed himself hard in the spring of $2002 \ldots$ devoting almost all his time' to the Everything and More project in order to complete 'a draft... just before leaving' [5, p. 274]. Wallace's suggestive note written on Cohen's letter-'Arrive by July 11'supports Max's claim that Wallace intended to deliver a manuscript before he left Bloomington, and specifically identifies a proposed deadline 6 months from Wallace's correspondence with Cohen in October 2000.

The resulting book, Everything and More: a Compact History of Infinity [11] is more an emotive depiction of transfinite mathematics than a sober biography of Cantor or an intellectual textbook explicating his method. This makes Everything and More a unique entry in the Great Discoveries series: unlike Quammen's The Relucant Mr. Darwin [9], for example, Wallace's text is no 'concise treatment, part narrative and part essay, accurate but pleasantly readable, of [a] huge and deeply complicated subject' $[9$, p. 18]. The book is the longest entry in the series to date, ${ }^{3}$ its 336 pages testify to what Wallace identified early in his correspondence with Cohen: 'that the implications/ramifications of Cantor's diagonal proof are huge... it would take 500 pages even to outline these consequences and ramifications'. Yet, even though Wallace does not dwell on these consequences, the issue of length is compounded by the book's formal peculiarities. The concepts exposed in Everything and More are not presented in the clear, linear

\footnotetext{
${ }^{2}$ A limit Wallace would far exceed with the final book's $336 \mathrm{pp}$.

3 Although Lawrence M. Krauss's Quantum Man [4] is 368 pp., a large proportion of Wallace's text is in three-point type.
}

manner of a biography, nor are they treated didactically in an accretive method designed to lead the student from one difficult concept to the next, where progression is only possible by mastering each consecutive stage. Rather, Everything and More is an idiosyncratic product, complete with all the requisite Wallaceian footnotes and conspicuous authorial interpolations, that doesn't so much train the reader in Cantorian mathematics as it does enact the difficulties of mathematical abstraction as it relates to our everyday lives and narratives.

Despite undergoing extensive editing (including a manuscript review by a Norton-commissioned mathematician who had 'serious reservations and pointed to errors, some small, some larger in it', Everything and More was published in October 2003 to hostile reviews from the scientific community [5, p. 275]. Even Science (to which Wallace had earlier contributed an article criticising the sloppiness of fictional representations of mathematics [10]) printed Rudy Rucker's caustic assessment [8] which catalogued the 'crippling errors' [8, p. 313] of a book that should at best be viewed with 'sardonic amusement' by the scientific community. Whilst not all reviews were (wholly) negative (see, for example, [3] and [7]) there was a reaction significant enough to prompt the staff at Norton to take note of suggested revisions, especially from wallace-l's mathematically-trained contributors Jordan Ellenberg and Prabhakar Ragde, ${ }^{4}$ to the point of requesting that Ragde subject the text to yet another proof-reading prior to a paperback edition. However, Wallace opposed many of Ragde's suggestions: the book was for the general reader, the author explained, not for the specialists [5, p. 276].

Though resistant to Ragde's corrections, Wallace did require a mathematical cicerone to 'walk [him] through any hairy symbolism' that would inevitably be encountered in studying Cantor's set theory. For this, he did not turn to a professional mathematician, but to a young postgraduate student in his father's philosophy department at the University of Illinois-Erica L. Neely. A mathematical prodigy, graduating from Oxford University's rigorous B.A. course at the age of seventeen, Neely's background suitably qualified her, to Wallace's mind, as his technical assistant on the project and they consulted for an hour on the phone in the autumn of 2000. Between May 2001 and May 2002 Wallace and Neely corresponded by phone, email, and letters. Initially their discussions concerned Wallace's chosen sources: Carl Boyer's A History of Mathematics and Joseph W. Dauben's Georg Cantor: His Mathematics and Philosophy of the Infinite, the latter being 'quite technical and hard' according to Wallace. Neely supplemented this reading with extended explanations and examples of terms

\footnotetext{
${ }^{4}$ Ragde, Prabhakar, "E\&M Errata", Online posting. Wallace-1 (November 12, 2003). Accessed 26 Dec 2015.
} 
such as 'convergence' and 'cardinality,' taking the author through the relevant symbolism step by step when necessary. Their correspondence then evolved to account for such metaphysical concerns as the implications of using Cantor's set theory as a response to the paradoxes of the Ancient Greek Zeno. By the fourth of October 2001, Wallace had 'worked up to' Dauben's text and required Neely's parsing of much of the content: 'point set[s]', '[a]ccumulation point', 'real-line topology' and '[o]scillating functions'. Neely conceded that she was 'glad' Wallace didn't 'plan[] on using too much of [Dauben's] chapter one in your book; it is quite technical'. A few days later, Wallace describes Dauben's second chapter as 'hairy', suggesting Neely, 'as a Tutor For the Slow', provide explanations of the representation of a function and singularities 'in terms that would be understandable to, say, a normal 19-year-old with one semester of calculus'. Finally, Neely proof-read drafts of the entire book, tasked with identifying any glaring mathematical and descriptive errors: at stake was the balance between technical rigour and clarity for a general audience. In the late-Spring of 2002, Wallace sent a four-page draft manuscript to Neely, apologizing for 'the clunky prose [:] it's a draft'. Though commenting that 'By and large, things were good' on 6 May 2002 Neely also suggested corrections, which were on the whole positively received by Wallace. It was at her request, for example, that Wallace clarified the manuscript's aim of proving ' $\operatorname{Lim}_{n \rightarrow \infty}\left(1-\frac{1}{2^{n}}\right)^{n}=1$, hence 1 is the sum of $s_{n}$ ' with the addition of 'Hence you really can cross the street' in the published text [11, p. 195]. He also removed his implied (false) equivocation of Bolzano's 1830 theorem (that a continuous function $f( \pm x)$ in a closed interval must cross the $x$-axis) with the Intermediate Value Theorem, instead noting that the latter is a 'direct consequence' [11, p. 189] of the former in a footnote. Owing to her unique position of insight into Wallace's creative process, we asked Erica Neely, now an Assistant Professor of Philosophy at Ohio Northern University, for her recollections of creating Everything and More.

Stuart James Taylor (SJT): How did you come to work with David Foster Wallace?

Erica L. Neely (ELN): I studied Mathematical at Somerville College, University of Oxford, from 1994 to 1997 graduat[ing] with my B.A. at the age of 17 , along with the firm conviction that I didn't want to be a mathematician- I wanted to study philosophy.... I was a good mathematician. However, I wasn't a great mathematician. I didn't particularly want to spend my entire life frustrated by being almost good enough. [Also] Maths gets increasingly narrow as you go on.... Philosophy has many interconnections, which makes it easier to follow one thread to another, related area, and follow up your interests there. I never thought I'd get bored doing philosophy.... I spent a year applying to various programs and ended up at Illinois, in part because Bob Wengert (the chair at the time) was very enthusiastic....

My understanding is that David grew up knowing the Wengerts (since Jim Wallace was at Illinois for his entire career), and so one day he was talking to Bob about how he needed a technical consultant for this book he was writing. Bob recommended me to David because I had so much mathematical background. (At Oxford we didn't really study anything except mathematics, so it was pretty much equivalent to having a Master's in the US. Plus Bob knew I could talk to non-mathematicians, which probably was one of the reasons he suggested me). David was a little hesitant at first because I think he was afraid I was some child prodigy who wouldn't be able to talk to a non-mathematician, but that didn't end up being a problem. We talked on the phone and seemed to get along okay, so he hired me. (As a grad student, I was always happy to have some extra money!) [...At that point] I hadn't actually connected 'David, the son of Professor Wallace in our department' with 'David Foster Wallace'. Which probably sound[s] really dumb. However, I didn't really put it all together until partway through working with David. So while I had read a few short stories/essays of DFW's and enjoyed them, I didn't realize that's the person I was working for. Which is probably just as well-I couldn't really become retrospectively intimidated, so it was all okay.

SJT: What were your initial reactions to the proposed project that was to become Everything and More?

ELN: [David] said he was going to write a popular book on Cantor as part of a series. [... I thought] 'Who the hell reads a popular book on Cantor?' However, as he wished to pay me I was happy to answer whatever questions he wanted. Also, both Bob Wengert and Jim Wallace were really nice, so if they wanted me to help, I was happy to help, even if the project seemed a little weird.

SJT: What was to be your 'official' role as you understood it?

ELN: Essentially my understanding was that I would answer any questions on Cantor-related mathematics that he had, along with perhaps reading over the manuscript for technical details. (So not proofing for grammatical mistakes or anything, but checking to make sure the technical details seemed okay.) [Gradually,...I] got the impression that it wasn't supposed to be hugely technical, although some degree of that is inevitable in a math book... I can't actually remember if we agreed on the proofing stuff at first, or if that came later.

SJT: According to D.T. Max's biography, Wallace excelled in formal logic when he could express himself in a conversational tone, but 'analytic philosophy also required formal mathlike notations. Wallace, for all his gifts of 
mimicry, didn't know how to do them. He avoided straight math classes at Amherst, afraid they might lower his grade point average. ${ }^{5}$ He was aware how odd this looked: being good at the theory of math without being able to solve math problems. 'It seems sort of cheaty,' he had written [his friend] Washington his junior year...' [5, p. 42]. Did this project strike you as mimicry or genuine; was Wallace more 'cheaty' or authentic? Did your opinion change?

ELN: Hmm. I'm not sure that I think people who understand theory but can't do the problems are 'cheaty'. Honestly, I think the majority of the market for popular math books is precisely the set of people who understand theory but either can't or don't want to do the problems.... In any case, David seemed genuinely excited by the project-he didn't seem inauthentic in any fashion to me. Mostly I answered questions/explained things. I think he ended up using some of my explanations in the book, but I don't remember the details. (He always asked permission-he didn't 'steal' explanations or anything. It's just that this was more than a decade ago, so the details are a bit fuzzy to me at this point)... Honestly, the difficulties stemmed far more from David's ineptitude with machines than with any problems he had with math. The reason I started writing him letters is that I discovered he couldn't figure out how to print or save his emails and was copying them out by hand. (Admittedly, I was thrilled not to have to write equations in ASCII anymore, so the switch to physical letters made me quite happy). I didn't particularly find him slow, just not as educated in mathematics... He said that he had been reading those books [Boyer and Merzbach, A History of Mathematics; Dauben, Georg Cantor: His Mathematics and Philosophy of the Infinite; Quine, Set Theory and Its Logic; Berlinski, A Tour of the Calculus; and Huntington, The Continuum and Other Types of Serial Order] and wanted me to read them so that if he had questions he could come to me; other information that I had on the mathematical side of things came out my notes/ references from Oxford. If he'd asked me to find him more references, I'd certainly have been happy to. However, I rather suspected he knew more about Cantor himself than I did; I just knew more about the math.

SJT: Jesse Cohen was 'Not interested in a lot of technical symbolism e.g. trig functions' but rather intended a focus on 'Intutionism vs. Formalism/Platonism'? This briefing seems to specify a (meta-)philosophical approach-one that is arguably 'softer' on the general reader (than the purely mathematical). Mathematical Critics like Michael Harris concur, illustrating that Wallace's 'preoccupation with infinity here, and presumably in his fiction as well, is ultimately metaphysical' [2, p. 634].

\footnotetext{
5 As was revealed later, he got a D in the only Calculus class he took [6].
}

What were your thoughts of the balance between philosophy and mathematics as the project developed?

ELN: I think that it's something David wrestled with. I wasn't a philosophical consultant on the book, so if he was discussing the metaphysical issues with someone, it wasn't primarily with me. (Of course, growing up with his father at Illinois and friends with a bunch of the other profs here, he undoubtedly had people to spare that he could discuss the metaphysics with). I did wonder exactly why he'd picked Cantor as a subject, and it seems likely that it is the focus on infinity which interested him. (While I seem to recall we did talk about some philosophical questions (like the intuitionism/formalism stuff), metaphysics isn't one of my primary areas of interest, so I wouldn't have been a great resource for him anyway.)

SJT: After the publication of Everything and More, Wallace was criticised for insisting 'on the distinction between Fourier series and general trigonometric series, without making clear how they differ beyond saying that the former have Fourier coefficients, which are 'so conceptually hairy that we plan to avoid them at almost any cost' [11, p. 116; 3, p. 638]. This is the primary/basic definition that you gave Wallace in correspondence (clearly just for basic illustrative purposes: that a trigonometric series is a Fourier series without the Fourier coefficients). Do you think he was being 'cheaty' by not attempting a definition of a trig. series that didn't involve Fourier (i.e., one that would be easier, and/or more intuitive, for the 'general reader' to follow)? If so, do you think this is because he just didn't get it?

ELN: Hmm. I kind of got the feeling that he wasn't sure exactly how to pitch the book. Remember when I said 'who the hell would read a popular math book about Cantor?' Well, I wasn't being entirely facetious. Because a lot of what Cantor was working on is fairly technical, I really wasn't sure how to frame a book that was (a) accessible to a layperson while (b) maintaining sufficient intellectual rigor (or at least not seeming too false). I'm not sure David figured it out either, but I think that he was trying hard to avoid stickiness where he could because there was so much technical information which he had to put in. I don't know whether he had pressure from the publisher, or whether it was his own sense of trying to make the book more accessible to people. Unfortunately, his choices weren't necessarily always the best and I was definitely not the right person to be able to catch that all the time because I had too much background to be a good reader for that. I could help with technical stuff, and I could certainly try to find places where he might need to explain more... but sometimes it wasn't immediately obvious to me what we should have explicated more.

I never really felt like David was being 'cheaty' or trying to be 'cheaty', because he generally seemed to 
understand all the math after we discussed it. Of course, understanding math well enough to talk about it with another person who understands it is rather different than understanding it well enough to explain it to someone who doesn't. It may be that (like some undergraduates!) he thought he understood it at the time and later discovered he didn't understand it as well as he thought. But I can't really guess as to whether this was the case. I do know that in general he seemed quite happy to ask questions and get clarifications (multiple times if need be) and that he generally seemed to understand the concepts after we'd discussed them...

SJT: Critics like Jim Holt [3] (and, to some extent, Harris [2]) entertain the possibility that the mathematical mistakes in the book are in fact crucial to its aim, i.e., that they are a means for Wallace to disrupt/interrogate authorial authority. Indeed, the book's title alludes to Jorge Luis Borges's meditation on Shakespeare's protean authoridentity, 'Everything and Nothing', while the 'Ancient Greek' epitaph, as Wallace explained to Caleb Crain, was inauthentic_-Wallace supposedly made it up! [1, p. 125]. Do you think Wallace was falling on this playful/satirical side of the fence, rather than that of authenticity/sincerity?

ELN: Hmm. I don't think you can be playful/satirical about something (or at least that you can't do it well) without actually understanding the topic you are satirizing. So I think that in order to be playful, David did have to understand what he was talking about. I do think that David had a light-hearted tone in places, and we did occasionally discuss whether he'd taken it too far. (Okay, as I recall, my comment was something like that a particular footnote made me want to throw the manuscript across the room.) I never really got the sense that David was trying to make mistakes, however, so much as simplifications for a lay audience. Whether in some cases he simplified to the point of mistake is a reasonable question, of course.

SJT: What was your experience of the 'aftermath' of the publication?

ELN: I didn't really have one. David sent me a signed copy of it after it was published, and I put it on a shelf with my other popular math books. Having worked on it this long, I honestly was quite content not to even think about it for a while. I didn't follow up on it much, since I was pretty buried in my dissertation at that point.... [so] I didn't know there were a slew of negative reviews... I suspect that anyone writing a popular math/science book runs the risk of messing up the technical points (or messing up conveying the technical points), particularly if the subject matter is complex. It would never have occurred to me that this would be deliberate; David always seemed sincere in his desire to understand/communicate information. However, he did also clearly have a playful streak, so I suppose it is possible.

Open Access This article is distributed under the terms of the Creative Commons Attribution 4.0 International License (http://crea tivecommons.org/licenses/by/4.0/), which permits unrestricted use, distribution, and reproduction in any medium, provided you give appropriate credit to the original author(s) and the source, provide a link to the Creative Commons license, and indicate if changes were made.

\section{References}

1. Crain, C.: Approaching infinity. Boston Globe (October 26, 2003). Rpt. In: Burn, Stephen J. (ed.) Conversations with David Foster Wallace. University of Mississippi, Jackson (2012)

2. Harris, M.: A Sometimes Funny Book Supposedly about Infinity. Notices of the AMS 51(6), 632-638 (2004)

3. Holt, J.: To Infinity and Beyond. The New Yorker, 27 October 2003: 1-3 (2003)

4. Krauss, L.M.: Quantum Man: Richard Feynman's life in science. W.W. Norton, New York (2011)

5. Max D. T.: Every love story is a ghost story: a life of David Foster Wallace. London, Granta (2012)

6. NPR: 'Infinity: with David Foster Wallace' 13 October 2003, http://www.npr.org/templates/story/story.php?storyId=1464156. Accessed 26 Dec 2015

7. Paulos, J.A.: Everything and more: a compact history of infinity (Book Review). American Scholar 250(41), 71 (2003)

8. Rucker, R.: Infinite confusion. Science 303 (16 January 2004): 313-314 (2004)

9. Quammen, D.: The Relucant Mr. Norton, Darwin. New York (2007)

10. Wallace, D. F.: Rhetoric and the Math Melodrama. Science 290 (5500) (22 December 2000): 2263-2267 (2000)

11. Wallace, D. F.: Everything and More: A Compact History of Infinity. New York, W.W. Norton (2003); rpt. London, Phoenix (2005)

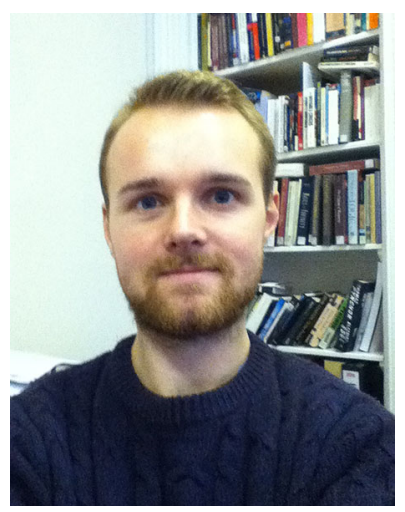

Stuart James Taylor is a doctoral candidate at the University of Glasgow. His dissertation examines the relationship between mathematics and contemporary American literature, specifically in the works of David Foster Wallace. 